\title{
FUTURE TRENDS AND PERSPECTIVES OF QUANTITATIVE CLINICAL PROTEOMICS
}

San Juanita Muñoz, ${ }^{1,2}$ Lokai Miranda Lui, ${ }^{1}$ and Hon-chiu Eastwood Leung ${ }^{1,2,3,4}$

${ }^{1}$ Mass Spectrometry Core Lab; ${ }^{2}$ Alkek Center for Molecular Discovery; ${ }^{3}$ Department of Molecular and Cellular Biology; ${ }^{4}$ Dan L. Duncan Cancer Center, Baylor College of Medicine, Houston, Texas, 77030, USA.

\section{Emails:}

San Juanita Muñoz: SanJuanita.Munoz@bcm.edu;

Lokai Miranda Lui: Lokai.Lui@bcm.edu;

Hon-chiu Eastwood Leung: hleung@bcm.edu

\begin{abstract}
:
Protein quantitation is an important clinical parameter for diagnosis, prognosis, and treatment monitoring such as drug response. In the past the assays were done mostly using antibody-based immunoassays such as radio-immunoassay (RIA) assays or enzyme-linked immunosorbent assay (ELISA). As novel changes that locate beyond the epitopes regions recognized by the antibody render the immunoassays non useful, detection methods that can sense chemical structural changes becomes desirable. Mass spectrometry offers speed, versatility, and sensitivity for the assay without the needs of a priori knowledge of the target molecules. The instrument can measure thousands of proteins (proteomics) simultaneously without losing the sensitivity. Specific novel mass spectra denote specific novel modifications on the target molecules. The report reviews quantitative proteomics using mass spectrometry with emphasis on biomarkers for diagnostics; biological fluids proteomics, tagging functional groups of proteins and eventually non-tagging quantitative proteomics which can offer great potential for emerging biomedical advanced technologies for better management of diseases.
\end{abstract}

Key words: immunoassays; biomarkers; mass spectrometry; quantitative proteomics 


\section{QUANTITATION USING IMMUNOASSAYS}

Immunoassays are currently the robust work horse in clinical setting for measuring quantitation of proteins. The assays can be in form of radio-immunoassay (RIA), enzyme -linked immunosorbent assay (ELISA), Western blotting, or immunohistochemistry (IHC). All these assays utilize the ability of antibody recognizing the specific epitope of the target protein. RIA was slowly replaced by ELISA because i) the hazard in handling radioactive material and higher sensitivity using fluorescence tag in ELISA. Western blotting and IHC are limited to low throughput assays because of the long processing time. The sensitivity of ELISA can reach to nanogram or subnanogram per milliliter level with good linearity (Sharma, Irshad et al. 1989, elShabrawi, Livir-Rallatos et al. , Petzold, Altintas et al. 2010). Microtiter plate format in lieu of multiplexed assays greatly enhances the throughput of the assays, and therefore is still the preferred method in clinical laboratories today.

However, antibody-based assays may need to consider the following limitations: 1) the higher cost and lead time of greater than 12 month in antibody generation, 2) the antibody may recognize the same epitope of a class of proteins or proteoforms (Little and Roberts 2009, Smith, Kelleher et al. 2013) that share similar epitopes and thus the specificity is limited, and 3) the presence of autoantibodies. An autoantibody is an antibody produced by the immune system that is directed against one or more of the individual's own proteins. These autoantibodies bind to the endogenous antigens and therefore reduce the concentration of the available antigen to be captured by the assay antibody. The detection of the presence of autoantibodies will then be an alternative approach provided that the window of detection is correct.

\section{APPLICABILITY OF MASS SPECTROMETRY IN PROTEOMICS}

Proteomics is the analysis of all the protein species in structure and function. Such a large scale of analysis has been performed using two-dimensional gel (2D gel) electrophoresis since 1975 (Klose and Spielmann 1975). The position and intensity of a particular spot in the gel in disease versus control samples reveal simple quantitative proteomics. However, wellresolved gel spots on 2D gel may not lead to good identification due to the limitation of protein sequencing method using Edman degradation. Mass spectrometry was used to analyze the mass over charge ratio of small molecules. There were many different forms of ionization and dissociation methods such as fast atom bombardment, chemical induction, matrix assisted laser desorption and ionization (MALDI), and electrospray ionization (ESI). MALDI and ESI are particularly useful as they are soft desorption ionization methods, i.e., there is a very low level of fragmentation of molecules upon gas phase conversion of ions. Molecules remain intact throughout the fly time. Therefore the mass over charge analyses of large intact molecules such as 
DNA or proteins become possible. The inventors, John Fenn and Koichi Tanaka, of these two soft ionization methods were awarded with Nobel Prize in chemistry in 2002 for their development of identification and structural analysis of biological macromolecules methods using soft desorption ionization mass spectrometry.

Once the molecules are in the form of gas phase ions, they are forced to fly through a vacuum tube via electric repulsion from the entrance of the tube. The first round $(\mathrm{Q} 1)$ of mass over charge is measured by collecting the time of flight of the molecules. The molecules are subjected to fragmentation either by electron capture or chemical induced collision with inert gas in the collision chamber (Q2). The subsequent fragmented ions (product ions) are analyzed again by measuring the time of flight (Q3) to the detector. Once the ions reach the detector, an increase in voltage potential is recorded in the peak's shape. The time of flight of a particular fragment ions are inversely proportional to their molecular mass over charge ratio. The peak height indirectly reflects the abundancy of the molecules. As the sensitivity and resolution of the mass spectrometer increased, internal peptide sequencing becomes possible with the advent of corresponding database development (Qin and Chait 1997, Qin, Fenyo et al. 1997, Fenyo, Qin et al. 1998). The advantage of using mass spectrometry is the sensitivity and versatility of measuring novel modifications on the peptides without a priori knowledge requirement of the target molecules. There are two approaches for protein sequencing: 1) a top-down approach, and 2) a bottom-up approach. The top-down approach was the sequencing of the whole intact protein molecule using a high-end mass spectrometer such as a Fouriertransform ion cyclotron resonance mass spectrometer. The protein was fragmented more comprehensively using electron capture dissociation or electron transfer dissociation. However the size limit of the molecules is approximately $30 \mathrm{kDa}(\mathrm{Sze}, \mathrm{Ge}$ et al. 2002, Sze, Ge et al. 2003). The bottom-up approach uses protease to digest the protein into peptides. Internal peptide sequencing generates overlaps of short peptide sequences. These sequences are used to match sequences from a database; thus deducing the full-length protein sequence.

Shotgun proteomics research during the past 15 years has principally focused on profiling (cataloging) comprehensively expressed proteins in case versus control samples in the hopes of discovering useful biomarkers associating with the case conditions (Omenn 2004, Tammen, Schulte et al. 2005, Engwegen, Helgason et al. 2006, Hamacher, Apweiler et al. 2006, Omenn 2007, Wang, Gu et al. 2007, Taguchi, Politi et al. 2011, Fuhrman, Schairer et al. 2012, Moore, Pfeiffer et al. 2012). As the search for biomarkers persists, the mere identity of proteins present in certain samples becomes inadequate. In order to reveal information on protein dynamics, relative protein quantities among different samples should also be addressed. Since mass spectrometry is in itself a qualitative method, various modifications have been implemented to obtain quantitative information from the proteomes over the past decade. The approach, termed quantitative proteomics, can be subdivided into two areas: 1) labelbased quantitative proteomics, and 2) labelfree quantitative proteomics. 


\section{QUANTITATIVE PROTEOMICS}

\subsection{LABEL-BASED QUANTITATIVE PROTEOMICS}

The first labelling approach was undertaken with $2 \mathrm{D}$ gel where one sample was labeled with $\mathrm{Cy} 3$ dye and another sample labeled with Cy5 fluorescent dyes in vitro (Gharbi, Gaffney et al. 2002, Zhou, Li et al. 2002). Samples were pooled and run in the gel together. Imaging of the differential fluorescent intensity of spot at the same location of the gel presumed to reveal the relative concentration of the same protein between the two samples. However, the identity of the protein spot was not known without mass spectrometry analysis.

In order to reveal the identity and quantitation, a direct mass spectrometry method was introduced. A particular functional group on a protein can be labelled in vivo or in vitro. As for in vivo method, cell cultures were grown in either light $\left({ }^{14} \mathrm{~N}\right.$ and $\left.{ }^{12} \mathrm{C}\right)$ or heavy $\left({ }^{15} \mathrm{~N}\right.$ and ${ }^{13} \mathrm{C}$ labelled arginine and lysine) medium. This metabolic labelling method is also called stable isotope labelling in cell culture (SILAC)(Ong, Foster et al. 2003, Mann 2006, Neher, Villen et al. 2006, Neubert and Tempst 2010). The heavy isotope-labeled amino acids are supposed to replace the majority of the endogenous light amino acids. The two type of samples were pooled and undergone the same protease treatment. The pairs of peptides with set $10 \mathrm{Da}$ shifts in mass delineate the peptide pairs from case and control samples. The relative intensities reveal the relative abundances of the peptides in two samples. This method can only be applied to cell cultures and can be economically prohibitive if large scale labelling is needed. For clinical samples or biological fluid, an in vitro labelling method will be needed.

Unlike SILAC which is only suitable for cell cultures, a wide variety of sample types can be either chemically or enzymatically labelled in vitro. Chemical labelling can be achieved via sulfhydryl group on cysteine residues, amino moiety at $\mathrm{N}$-terminal, or epsilon amino group of lysine residues. The first in vitro cysteine labelling approach used an isotope-coded affinity tag (ICAT) to label the sulfhydryl group of cysteine residues (Gygi, Rist et al. 1999). Although further development was geared toward more structurally stable linker and higher multiplex capability, the low percentage of proteins with cysteine residues rendered this method to have less utility. Amino labelling can be achieved using dimethylation or isobaric tags. A dimethylation reaction is based on the reaction of primary amine with formaldehyde between $\mathrm{pH} 5$ and 8.5 to generate a Schiff base that is rapidly reduced by the addition of cyanoborohydride to the mixture. The reaction can be used as a triplex reagent. The light version of formaldehyde, an intermediate version of deuterium formaldehyde and a heavy version of ${ }^{13} \mathrm{C}$ and deuterium generates differences of four to eight $\mathrm{Da}$ to the modified lysine residues (Boersema, Aye et al. 2008). If the experimental objective calls for a high order of multiplex, then an isobaric tag approach should be used.

Tandem mass tag (TMT) (Thompson, Schafer et al. 2003), isobaric tag for relative and absolute quantification 
(iTRAQ) (Ross, Huang et al. 2004), or isobaric peptide terminal labeling (IPTL) (Arntzen, Koehler et al. 2011) were offered commercially to allow up to 8-plex comparison in the same experimental run. The derivatized peptides are isobaric and chromatographically indistinguishable. Upon fragmentation, however, different mass tags (reporter ions) are observed and the peak areas denote the relative concentration of the same sequence of peptides in different samples. Clinical researchers can achieve absolute quantification if stringent control-on-loading and labeling reactions are conducted. We have performed an inter laboratory comparison using the same aliquots of iTRAQ labeled immuno-depleted plasma and found significant overlap results among different mass spectrometers (Jones, Kim et al. 2013). The only drawback is that only one peptide intensity was scored in $\mathrm{MS}^{1}$ scan; therefore, it may lead to lower overall intensity. Also, variables such as ratio compression and reporter ion dynamic range cause changes in relative abundance of proteins across samples to be underestimated and undermines the ability of the isobaric labeling approach to be truly quantitative (Rauniyar and Yates 2014).

Enzymatic labelling in vitro involves the presence of $\mathrm{H}_{2}{ }^{18} \mathrm{O}$ instead of normal $\mathrm{H}_{2}{ }^{16} \mathrm{O}$ during class-2 protease such as trypsin digestion. The process causes the exchange of two ${ }^{16} \mathrm{O}$ atoms for two ${ }^{18} \mathrm{O}$ atoms at the carboxyl group of the $\mathrm{C}$ terminal residue, resulting in a mass shift of four Daltons between differentially labeled peptides. Such a simple and economical approach was used to quantify protein differences in cell culture (Blonder, Hale et al. 2005), serum or plasma (Hood, Lucas et al. 2005, Qian, Monroe et al. 2005). This method was extended to study phosphoproteome changes between samples (Winter, Seidler et al. 2009).

\subsection{LABEL FREE QUANTITATIVE PROTEOMICS}

Recently, there has been a growing interest in label free quantitative proteomics. Protein mixtures in each sample are analyzed directly and samples are compared to each other after mass spectra are scored. As a result, there is not a mixing of samples and no tagging of peptides. The coverage should be expected to be the highest with this approach. Another advantage is that there is no apparent limitation on the number of samples to be analyzed simultaneously. There are essentially three strategies on tackling the quantitation problem.

The first strategy is comparing the total precursor ion count in the Q1 stage (before fragmentation) of target molecules among groups of samples. This method is measuring the area under the curves of particular target molecules at specific retention time and mass over charge ratio (Wiener, Sachs et al. 2004, Listgarten and Emili 2005, Listgarten and Emili 2005, Silva, Denny et al. 2005, Listgarten, Neal et al. 2007). A researcher should exhibit precaution in sample preparation and normalization to ensure that the total amount of peptides loaded is kept constant. Additional concern is warranted regarding the accurate assignment of the peptide identity when complex samples are being measured, since peptides with very similar mass over charge ratio and retention time 
will mask the intensity of the target peptides. Also, a same peptide sequence with different post-translational modifications will shift the retention time and mass over charge measurement substantially.

The second strategy is the spectral counting approach in which the total number of MS/MS spectra (fragmented ions) of the same protein is compared amongst sample groups. This approach is based on the assumption that the higher the protein concentration is, the more tryptic peptides found for the protein; and therefore the higher number will be the fragmented peptides spectra count. This method was found to correlate stronger to protein abundance and to cover higher dynamic range (Liu, Sadygov et al. 2004, Zybailov, Coleman et al. 2005, Lundgren, Hwang et al. 2010). However, one should pay particular attention when the measurement is being used to check very low abundance proteins. The method suffers from few spectra counted and there is not a precursor peptide signal to correlate to the spectral counting data. Recently advancement in the data acquisition has implemented in a way of using a narrow sequential window acquisition for all theoretical MS spectra (SWATH) (Gillet, Navarro et al. 2012). The acquisition is done in sequential narrow windows such as 25 atomic mass units such that libraries of all observable peptides and the fragmented ions are built. These libraries will be very useful for stringent quantification of target molecules of interest in future data mining (Schubert, Gillet et al. 2015).

The third approach is the spike-in standard peptides so that absolute quantification of target molecules can be achieved. Light version $\left({ }^{12} \mathrm{C}\right.$ and $\left.{ }^{14} \mathrm{~N}\right)$ of the target peptides were made to optimize the instrument parameters and the limits of detection. Heavy isotopes version $\left({ }^{13} \mathrm{C}\right.$ and ${ }^{15} \mathrm{~N}$ ) of target peptides with particular sequences were spiked into the samples. As the absolute amount of the spike-in heavy standards are known and the ions peaks of the heavy peptides lie next to the endogenous light peptides, the absolute quantification of the endogenous target peptides can be deduced from the relative intensity of the ion pairs. This approach was tested in a large scale multi-laboratory setting and found to be very robust across different workflows (Carr, Abbatiello et al. 2014, Abbatiello, Schilling et al. 2015).

\section{PROSPECTUS FOR ROUTINE QUANTITATION}

Using complementary approaches with a variety of biological samples such as blood, serum, plasma, urine, proteomic quantitation can effectively identify new candidate protein biomarkers for diagnosis, prognosis, and as therapeutic targets for cancer, as well as to elucidate the molecular mechanisms of carcinogenesis. Highthroughput and accurate quantification of proteins is an essential component of proteomics strategies for studying cellular functions and processes. Advances in quantitative proteomics continue to provide important insights into many biological processes as well as add immense value in protein discoveries as biomarkers.

\section{FUTURE DIRECTION AND OUTLOOK}


As the resolution, sensitivity and reproducibility of mass spectrometry are improving, the proteomics workflow may one day be able to analyze quantitatively the whole proteome of any clinical sample. As a result, personalized medicine using complementary 'omics' approaches can be realized for better management of diseases. The workflow starts from genome wide DNA sequencing, whole exome RNA sequencing, proteome-wide quantitative proteomics, and metabolomics. Diagnosis, prognosis, and drug target development that are specific to an individual can be realistically achieved with not only minimal side effects, but a maximized cure rate. 


\section{REFERENCES}

Abbatiello, S. E., B. Schilling, D. R. Mani, L. J. Zimmerman, S. C. Hall, B. MacLean, M. Albertolle, S. Allen, M. Burgess, M. P. Cusack, M. Ghosh, V. Hedrick, J. M. Held, H. D. Inerowicz, A. Jackson, H. Keshishian, C. R. Kinsinger, J. Lyssand, L. Makowski, M. Mesri, H. Rodriguez, P. Rudnick, P. Sadowski, N. Sedransk, K. Shaddox, S. J. Skates, E. Kuhn, D. Smith, J. R. Whiteaker, C. Whitwell, S. Zhang, C. H. Borchers, S. J. Fisher, B. W. Gibson, D. C. Liebler, M. J. MacCoss, T. A. Neubert, A. G. Paulovich, F. E. Regnier, P. Tempst and S. A. Carr (2015). "Large-scale inter-laboratory study to develop, analytically validate and apply highly multiplexed, quantitative peptide assays to measure cancer-relevant proteins in plasma." Mol Cell Proteomics. Epub ahead of print. http://www.ncbi.nlm.nih.gov/pubmed/25693 $\underline{799}$

Arntzen, M. O., C. J. Koehler, A. Treumann and B. Thiede (2011). "Quantitative proteome analysis using isobaric peptide termini labeling (IPTL)." Methods Mol Biol 753: 65-76.

Blonder, J., M. L. Hale, K. C. Chan, L. R. Yu, D. A. Lucas, T. P. Conrads, M. Zhou, M. R. Popoff, H. J. Issaq, B. G. Stiles and T. D. Veenstra (2005). "Quantitative profiling of the detergent-resistant membrane proteome of iota-b toxin induced vero cells." J Proteome Res 4(2): 523-531.

Boersema, P. J., T. T. Aye, T. A. van Veen, A. J. Heck and S. Mohammed (2008). "Triplex protein quantification based on stable isotope labeling by peptide dimethylation applied to cell and tissue lysates." Proteomics 8(22): 4624-4632.

Carr, S. A., S. E. Abbatiello, B. L. Ackermann, C. Borchers, B. Domon, E. W. Deutsch, R. P. Grant, A. N. Hoofnagle, R. Huttenhain, J. M. Koomen, D. C. Liebler, T. Liu, B. MacLean, D. R. Mani, E. Mansfield, H. Neubert, A. G. Paulovich, L. Reiter, O. Vitek, R. Aebersold, L. Anderson, R. Bethem, J. Blonder, E. Boja, J. Botelho, M. Boyne, R. A. Bradshaw, A. L. Burlingame, D. Chan, H. Keshishian, E. Kuhn, C. Kinsinger, J. S. Lee, S. W. Lee, R. Moritz, J. Oses-Prieto, N. Rifai, J. Ritchie, H. Rodriguez, P. R. Srinivas, R. R. Townsend, J.Van Eyk, G. Whiteley, A. Wiita and S. Weintraub (2014). "Targeted peptide measurements in biology and medicine: best practices for mass spectrometry-based assay development using a fit-for-purpose approach." Mol Cell Proteomics 13(3): 907-917.

el-Shabrawi, Y., C. Livir-Rallatos, W. Christen, S. Baltatzis and C. S. Foster (1998). "High levels of interleukin-12 in the aqueous humor and vitreous of patients with uveitis." Ophthalmology 105(9): 1659-1663.

Engwegen, J. Y., H. H. Helgason, A. Cats, N. Harris, J. M. Bonfrer, J. H. Schellens and J. H. Beijnen (2006). "Identification of serum proteins discriminating colorectal cancer patients and healthy controls using surface-enhanced laser desorption ionisation-time of flight mass spectrometry." World J Gastroenterol 12(10): 1536-1544. 
Fenyo, D., J. Qin and B. T. Chait (1998).

"Protein identification using mass spectrometric information." Electrophoresis 19(6): 998-1005.

Fuhrman, B. J., C. Schairer, M. H. Gail, J. Boyd-Morin, X. Xu, L. Y. Sue, S. S. Buys, C. Isaacs, L. K. Keefer, T. D. Veenstra, C. D. Berg, R. N. Hoover and R. G. Ziegler (2012). "Estrogen metabolism and risk of breast cancer in postmenopausal women." J Natl Cancer Inst 104(4): 326-339.

Gharbi, S., P. Gaffney, A. Yang, M. J. Zvelebil, R. Cramer, M. D. Waterfield and J. F. Timms (2002). "Evaluation of two-dimensional differential gel electrophoresis for proteomic expression analysis of a model breast cancer cell system." Mol Cell Proteomics 1(2): 91-98.

Gillet, L. C., P. Navarro, S. Tate, H. Rost, N. Selevsek, L. Reiter, R. Bonner and R. Aebersold (2012). "Targeted data extraction of the MS/MS spectra generated by data-independent acquisition: a new concept for consistent and accurate proteome analysis." Mol Cell Proteomics 11(6): O111 016717.

Gygi, S. P., B. Rist, S. A. Gerber, F. Turecek, M. H. Gelb and R. Aebersold (1999). "Quantitative analysis of complex protein mixtures using isotope-coded affinity tags." Nat Biotechnol 17(10): 994-999.

Hamacher, M., R. Apweiler, G. Arnold, A. Becker, M. Bluggel, O. Carrette, C. Colvis, M. J. Dunn, T. Frohlich, M. Fountoulakis, A. van Hall, F. Herberg, J. Ji, H. Kretzschmar, P. Lewczuk, G. Lubec, K.
Marcus,

L. Martens, N. Palacios Bustamante, Y. M. Park, S. R. Pennington, J. Robben, K. Stuhler, K. A. Reidegeld, P. Riederer, J. Rossier, J. C. Sanchez, M. Schrader, C. Stephan, D. Tagle, H. Thiele, J. Wang, J. Wiltfang, J. S. Yoo, C. Zhang, J. Klose and H. E. Meyer (2006). "HUPO Brain Proteome Project: summary of the pilot phase and introduction of a comprehensive data reprocessing strategy." Proteomics 6(18): 4890-4898.

Hood, B. L., D. A. Lucas, G. Kim, K. C. Chan, J. Blonder, H. J. Issaq, T. D. Veenstra, T. P. Conrads, I. Pollet and A. Karsan (2005). "Quantitative analysis of the low molecular weight serum proteome using 180 stable isotope labeling in a lung tumor xenograft mouse model." J Am Soc Mass Spectrom 16(8): 1221- 1230.

Jones, K. A., P. D. Kim, B. B. Patel, S. G. Kelsen, A. Braverman, D. J. Swinton, P. R. Gafken, L. A. Jones, W.

S.Lane, J. M. Neveu, H. C. Leung, S. A. Shaffer, J. D. Leszyk, B. A. Stanley, T. E. Fox, A. Stanley, M. J. Hall, H. Hampel, C. D. South, A. de la Chapelle, R. W. Burt, D. A. Jones, L. Kopelovich and A. T. Yeung (2013). "Immunodepletion plasma proteomics by tripleTOF 5600 and Orbitrap elite/LTQ-Orbitrap Velos/Q exactive mass spectrometers." J Proteome Res 12(10): 4351-4365.

Klose, J. and H. Spielmann (1975). "Gel isoelectric focusing of mouse lactate dehydrogenase: heterogeneity of the isoenzymes A4 and X4." Biochem Genet 
13(9-10): 707-720.

Listgarten, J. and A. Emili (2005). "Practical proteomic biomarker discovery: taking a step back to leap forward." Drug Discov Today 10(23-24): 1697-1702.

Listgarten, J. and A. Emili (2005). "Statistical and computational methods for comparative proteomic profiling using liquid chromatography-tandem mass spectrometry." Mol Cell Proteomics 4(4): 419-434.

Listgarten, J., R. M. Neal, S. T. Roweis, P. Wong and A. Emili (2007). "Difference detection in LC-MS data for protein biomarker discovery." Bioinformatics 23(2): e198-204.

Little, R. R. and W. L. Roberts (2009). "A review of variant hemoglobins interfering with hemoglobin A1c measurement." Diabetes Sci Technol 3(3): 446-451.

Liu, H., R. G. Sadygov and J. R. Yates, 3rd (2004). "A model for random sampling and estimation of relative protein abundance in shotgun proteomics." Anal Chem 76(14): 4193-4201.

Lundgren, D. H., S. I. Hwang, L. Wu and D. K. Han (2010). "Role of spectral counting in quantitative proteomics." Expert Rev Proteomics 7(1): 39-53.

Mann, M. (2006). "Functional and quantitative proteomics using SILAC." Nat Rev Mol Cell Biol 7(12): 952-958.

Moore, L. E., R. M. Pfeiffer, Z. Zhang, K.
H. Lu, E. T. Fung and R. C. Bast, Jr. (2012). "Proteomic biomarkers in combination with CA 125 for detection of epithelial ovarian cancer using prediagnostic serum samples from the Prostate, Lung, Colorectal, and Ovarian (PLCO) Cancer Screening Trial." Cancer 118(1): 91-100.

Neher, S. B., J. Villen, E. C. Oakes, C. E. Bakalarski, R. T. Sauer, S. P. Gygi and T. A. Baker (2006). "Proteomic profiling of ClpXP substrates after DNA damage reveals extensive instability within SOS regulon." Mol Cell 22(2): 193-204.

Neubert, T. A. and P. Tempst (2010). "Super-SILAC for tumors and tissues." Nat Methods 7(5): 361-362. Omenn, G. S. (2004). "Advancement of biomarker discovery and validation through the HUPO plasma proteome project." Dis Markers 20(3): 131-134.

Omenn, G. S. (2007). "THE HUPO Human Plasma Proteome Project." Proteomics Clin Appl 1(8): 769-779. Ong, S. E., L. J. Foster and M. Mann (2003). "Mass spectrometric-based approaches in quantitative proteomics." Methods 29(2): 124-130.

Petzold, A., A. Altintas, L. Andreoni, A. Bartos, A. Berthele, M. A. Blankenstein, L. Buee, M. Castellazzi, S. Cepok, M. Comabella, C. S. Constantinescu, F. Deisenhammer, G. Deniz, G. Erten, M. Espino, E. Fainardi, D. Franciotta, M. S. Freedman, V. Giedraitis, N. E. Gilhus, G. Giovannoni, A. Glabinski, P. Grieb, H. P. Hartung, B. Hemmer, S. K. Herukka, R. Hintzen, M. Ingelsson, S. Jackson, S. 
Jacobsen, N. Jafari, M. Jalosinski, S. Jarius, E. Kapaki, B. C. Kieseier, M. J. Koel-Simmelink, J. Kornhuber, J. Kuhle, J. Kurzepa, P. H. Lalive, L. Lannfelt, V. Lehmensiek, P. Lewczuk, P. Livrea, F. Marnetto, D. Martino, T. Menge, N. Norgren, E. Papuc, G. P. Paraskevas, T. Pirttila, C. Rajda, K. Rejdak, J. Ricny, D. Ripova, L. Rosengren, M. Ruggieri, S. Schraen, G. Shaw, C. Sindic, A. Siva, T. Stigbrand, I. Stonebridge, B. Topcular, M. Trojano, H. Tumani, H. A. Twaalfhoven, L. Vecsei, V. Van Pesch, H. Vanderstichele, C. Vedeler, M. M. Verbeek, L. M. Villar, R. Weissert, B. Wildemann, C. Yang, K. Yao and C. E. Teunissen (2010). "Neurofilament ELISA validation." $\underline{\mathrm{J}} \underline{\text { Immunol Methods }}$ 352(1-2): 23-31.

Qian, W. J., M. E. Monroe, T. Liu, J. M. Jacobs, G. A. Anderson, Y. Shen, R. J. Moore, D. J. Anderson, R. Zhang, S. E. Calvano, S. F. Lowry, W. Xiao, L. L. Moldawer, R. W. Davis, R. G. Tompkins, D. G. Camp, 2nd, R. D. Smith, Inflammation and P. the Host Response to Injury Large Scale Collaborative Research (2005). "Quantitative proteome analysis of human plasma following in vivo lipopolysaccharide administration using 160/180 labeling and the accurate mass and time tag approach." Mol Cell Proteomics 4(5): 700- 709.

Qin, J. and B. T. Chait (1997). "Identification and characterization of posttranslational modifications of proteins by MALDI ion trap mass spectrometry." Anal Chem 69(19): 4002-4009.

Qin, J., D. Fenyo, Y. Zhao, W. W. Hall, D. M. Chao, C. J. Wilson, R. A. Young and B.
T. Chait (1997). "A strategy for rapid, high-confidence protein identification." Anal Chem 69(19): 3995-4001.

Rauniyar, N. and J. R. Yates, 3rd (2014). "Isobaric labeling-based relative quantification in shotgun proteomics." $\underline{J}$ Proteome Res 13(12): 5293-5309.

Ross, P. L., Y. N. Huang, J. N. Marchese, B. Williamson, K. Parker, S. Hattan, N. Khainovski, S. Pillai, S. Dey, S. Daniels, S. Purkayastha, P. Juhasz, S. Martin, M. Bartlet-Jones, F. He, A. Jacobson and D. J. Pappin (2004). "Multiplexed protein quantitation in Saccharomyces cerevisiae using amine-reactive isobaric tagging reagents." Mol Cell Proteomics 3(12): 1154-1169.

Schubert, O. T., L. C. Gillet, B. C. Collins, P. Navarro, G. Rosenberger, W. E. Wolski, H. Lam, D. Amodei, P. Mallick, B. MacLean and R. Aebersold (2015). "Building high-quality assay libraries for targeted analysis of SWATH MS data." Nat Protoc 10(3): 426-441.

Sharma, M. P., M. Irshad and N. Verma (1989). "Serum alpha-feto protein in amoebic liver abscess." Indian J Med Res 90: $127-130$.

Silva, J. C., R. Denny, C. A. Dorschel, M. Gorenstein, I. J. Kass, G. Z. Li, T. McKenna, M. J. Nold, K. Richardson, P. Young and S. Geromanos (2005). "Quantitative proteomic analysis by accurate mass retention time pairs." Anal Chem 77(7): 2187-2200. 
Smith, L. M., N. L. Kelleher and P. Consortium for Top Down Proteomics (2013). "Proteoform: a single term describing protein complexity." $\underline{\mathrm{Nat}}$ Methods 10(3): 186-187.

Sze, S. K., Y. Ge, H. Oh and F. W. McLafferty (2002). "Top-down mass spectrometry of a $29-\mathrm{kDa}$ protein for characterization of any posttranslational modification to within one residue." Proc Natl Acad Sci U S A 99(4): 1774-1779.

Sze, S. K., Y. Ge, H. Oh and F. W. McLafferty (2003). "Plasma electron capture dissociation for the characterization of large proteins by top down mass spectrometry." Anal Chem 75(7): 1599-1603.

Taguchi, A., K. Politi, S. J. Pitteri, W. W. Lockwood, V. M. Faca, K. Kelly-Spratt, C. H. Wong, Q. Zhang, A. Chin, K. S. Park, G. Goodman, A. F. Gazdar, J. Sage, D. M. Dinulescu, R. Kucherlapati, R. A. Depinho, C. J. Kemp, H. E. Varmus and S. M. Hanash (2011). "Lung cancer signatures in plasma based on proteome profiling of mouse tumor models." Cancer Cell 20(3): 289-299.

Tammen, H., I. Schulte, R. Hess, C. Menzel, M. Kellmann, T. Mohring and P. Schulz-Knappe (2005). "Peptidomic analysis of human blood specimens: comparison between plasma specimens and serum by differential peptide display." Proteomics 5(13): 3414-3422.

Thompson, A., J. Schafer, K. Kuhn, S. Kienle, J. Schwarz, G. Schmidt, T. Neumann, R. Johnstone, A. K. Mohammed and C. Hamon (2003). "Tandem mass tags: a novel quantification strategy for comparative analysis of complex protein mixtures by MS/MS." Anal Chem 75(8): 1895-1904.

Wang, J., Y. Gu, L. Wang, X. Hang, Y. Gao, H. Wang and C. Zhang (2007). "HUPO BPP pilot study: a proteomics analysis of the mouse brain of different developmental stages." Proteomics 7(21): 4008- 4015.

Wiener, M. C., J. R. Sachs, E. G. Deyanova and N. A. Yates (2004). "Differential mass spectrometry: a label-free LC-MS method for finding significant differences in complex peptide and protein mixtures." Chem 76(20): 6085-6096.

Winter, D., J. Seidler, S. Ziv-Lehrman, Y. Shiloh and W. D. Lehmann (2009). "Simultaneous identification and quantification of proteins by differential (16) $\mathrm{O} /(18) \mathrm{O}$ labeling and UPLC-MS/MS applied to mouse cerebellar phosphoproteome following irradiation." Anticancer Res 29(12): 4949-4958.

Zhou, G., H. Li, D. DeCamp, S. Chen, H. Shu, Y. Gong, M. Flaig, J. W. Gillespie, N. Hu, P. R. Taylor, M. R. Emmert-Buck, L. A. Liotta, E. F. Petricoin, 3rd and Y. Zhao (2002). "2D differential in-gel electrophoresis for the identification of esophageal scans cell cancer-specific protein markers." Mol Cell Proteomics 1(2): 117-124.

Zybailov, B., M. K. Coleman, L. Florens and M. P. Washburn (2005). "Correlation of 
relative abundance ratios derived from peptide ion chromatograms and spectrum counting for quantitative proteomic analysis using stable isotope labeling." Anal Chem 77(19): 6218-6224. 